\title{
Self-Inflicted Gingival Injury Due to Habitual Fingernail Scratching: A Case Report with a 1-Year Follow Up
}

Alparslan Dilsiz

Tugba Aydin ${ }^{b}$

\begin{abstract}
Injuries to oral soft-tissues can occur due to accidental, iatrogenic, and factitious traumas. Traumatic lesions, whether chemical, physical, or thermal in nature, are among the most common in the mouth. A type of physical injury to the gingival tissues is self-inflicted. Sometimes the lesions are termed gingivitis artefacta. Self-inflicted gingival injuries in children and adolescents can occur as a result of accidental trauma, premeditated infliction, or chronic habits such as fingernail biting, digit sucking, or sucking on objects such as pens, pencils or pacifiers. The purpose of this case report was to illustrate the destructive nature of the habit and to describe the successful treatment of this case. A 14-year-old girl with moderate pain, gingival bleeding and recession in the anterior mandibulary region was admitted to periodontology clinic. Upon questioning, the patient readily admitted traumatizing her gingiva with her fingernail. Treatment consisted of oral hygiene instruction, mechanical debridement, psychological support and surgical periodontal treatment. Postoperatively, complete root coverage, gains in clinical attachment levels, and highly significant increases in the width of keratinized gingiva were observed. This case report shows that it is possible to treat gingival injury and maintain the periodontal health of a patient with destructive habit. Patient compliance, regular dental follow-ups, and psychological support may be useful in stabilizing the periodontal condition of these patients. Dentists must be aware that self-inflicted gingival injury, although thought to be uncommon, is quite widespread. (Eur J Dent 2009;3:150-155)
\end{abstract}

Key words: Gingiva/injuries; Gingival recession; Self-inflicted; Factitious disease; Habits/adverse effects; Free gingival graft.

assistant Professor, Department of Periodontology, Faculty of Dentistry, Ataturk University, Erzurum, Turkey.

b Post Graduate Student, Department of Periodontology, Faculty of Dentistry, Ataturk University, Erzurum, Turkey.

- Corresponding author: Alparslan Dilsiz Department of Periodontology, Faculty of Dentistry, Ataturk University, 25240, Erzurum, Turkey. Phone: +90 4422313967 Fax: + 904422360945 E-mail: aydilsiz@yahoo.com

\section{INTRODUCTION}

The current classification of periodontal diseases includes accidental, iatrogenic, and factitious traumatic lesions. ${ }^{1}$ Although the prevalence of traumatic gingival lesions is relatively high, there are limited reports on the diagnosis and management of these injuries. Traumatic lesions, whether chemical, physical, or thermal in nature, are among the most common 
in the mouth. A type of physical injury to the gingival tissues is self-inflicted. Sometimes the lesions are termed gingivitis artefacta. ${ }^{2-4}$ Selfinjurious behavior affecting the gingival tissues has minor and major variants. ${ }^{2}$ Gingivitis artefacta minor was recognized as being more common and thought to be provoked by a preexisting locus of irritation. This form results from rubbing or picking the gingiva using the fingernail, or perhaps from abrasive foods such as crisps. ${ }^{2,3,5}$ In this form, the habit was claimed to respond readily to simple treatment that removed the underlying source of irritation. The major form is more severe and widespread and can involve the deeper periodontal tissues. ${ }^{2,6}$ Other areas of the mouth such as the lips and tongue may be involved and extraoral injuries may be found on the scalp, limbs, or face. ${ }^{2}$ This type of behavior also differed in being more resistant to conventional forms of treatment and was probably associated with an emotional disorder. ${ }^{2,4}$

Self-inflicted oral injuries seem to be much more common in children than in teenagers and adults. Most of the reported cases have involved female patients. ${ }^{7}$ Although the gingiva is the most commonly targeted tissue, no structure in the oral cavity is immune from the effects of this type of behavior. Self-inflicted gingival injuries in children and young individuals can occur as a result of accidental trauma, premeditated infliction, or chronic habits such as fingernail biting, digit sucking, or sucking on objects such as pens, pencils, toothpicks, dental floss, or pacifiers. ${ }^{2-24}$ Most case reports suggest that the method of producing injury is by 'picking' or 'scratching' the gingival tissues with fingers or fingernails.

The purpose of this case report was to illustrate the destructive nature of the habit and to describe the successful treatment of this case.

\section{CASE REPORT}

A 14-year-old girl was referred by her dentist to the Periodontology clinic of the Faculty of Dentistry, Ataturk University, for evaluation and treatment of the gingival recession associated with the mandibular right incisor.

Upon questioning the patient, she admitted to have been "scratching" her gingiva with her fingernail for a long period of time. The patient further stated that this "scratching" habit occurred mainly time of exam. Her history gave no evidence of any known prior emotional disturbance. The patient had history of pain and sensitivity in this area. The patient's medical history was non-contributory and she did not take any medications.

Clinical evaluation revealed gingival recession on the buccal surface extending $3 \mathrm{~mm}$ apical to the cemento-enamel junction (CEJ) and a narrow zone of attached gingival measuring approximately $1 \mathrm{~mm}$ (Figure 1). There was loss of papilla height on the mesial aspect of the incisor and moderate gingival overgrowth on the distal aspect. The gingiva in these regions had edematous, reddish and ulcerated appearance. Plaque deposits were minimal.

Written informed consent was obtained from the patient's parent after all treatment procedures had been fully explained.

\section{Treatment considerations}

Rendering treatment in this case would help the dental problem but total treatment would require discovery and elimination of the intrinsic emotional factors and extrinsic contributing factors. Thus the patient was referred to a psychiatrist for evaluation and treatment. The damage caused by "scratching" was pointed out to the patient and she was convinced that she should discontinue this habit. Before surgical treatment of the gingival recession, the patient underwent scaling, root planning, crown polishing, oral hygiene instruction, and psychological support.

The goal of surgical periodontal treatment was to restore harmonious appearance of the gingiva by covering the root surface to an equal level of the neighboring teeth and, at the same time; to increase the zone of attached gingiva. It was decided to treat this problem with a free gingival graft (FGG).

\section{Surgical procedure}

The exposed root surface was carefully planed with the use of Gracey curettes. The area was gently irrigated with sterilized physiological saline solution. Before surgery, extraoral antisepsis was performed with 10\% Povidone-iodine solution. The defect was treated by approach described by Miller. ${ }^{25} \mathrm{~A}$ local anesthetic was administered to 
donor and recipient sites to achieve anesthesia.

Following local anesthesia, for preparing a recipient bed for the FGG, a horizontal incision was made at the level of the CEJ in correspondence to the base of adjacent papilla to the line angles of the neighboring teeth from which vertical incisions were realized to the apical extent of the recipient bed, $3 \mathrm{~mm}$ apical to the recession, such delimited tissue was then removed by a partial thickness incision. The graft of adequate size and of about $1.5 \mathrm{~mm}$ thickness was then harvested from the palate in correspondence to the bicuspid area by a partial thickness incision with a no.15 blade; within 1 min of removal, the graft was then sutured to the recipient bed by two lateral 4-0 silk sutures and was then stabilized by a toothsuspended 4-0 silk crossed suture (Figure 2); an attempt was made to place the coronal margin of the graft in correspondence to the CEJ. The

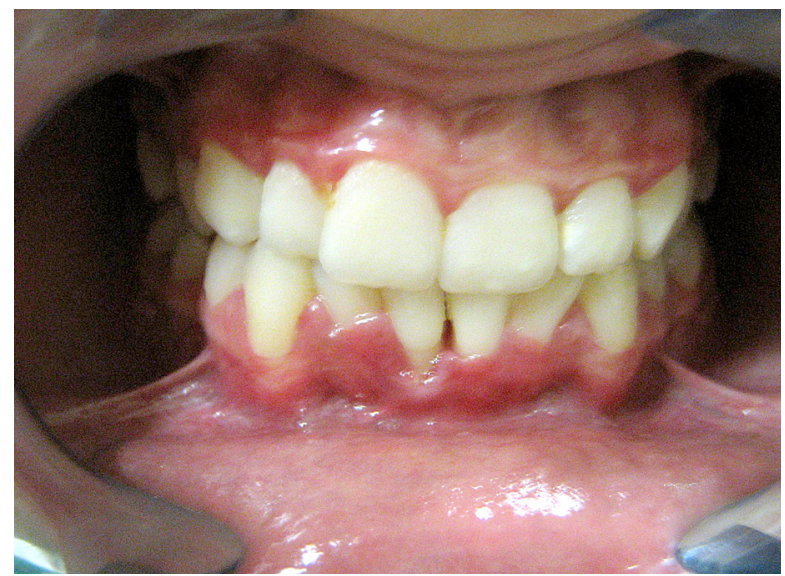

Figure 1. Self-inflicted gingival recession with edematous and ulcerated margin due to 14-year-old girl's scratching with fingernail.

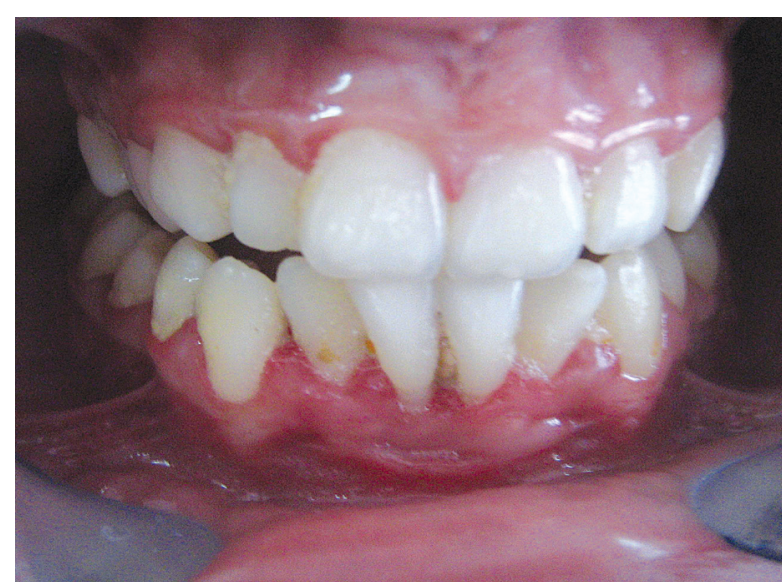

Figure 3. Clinical view at 4 weeks post-surgery. The surgical site is still edematous and reddish. grafted tissue was then compressed for about 5 min onto the recipient bed. The donor and recipient sites were protected with periodontal pack.

The patient was prescribed analgesics and instructed to rinse twice daily with $0.12 \%$ chlorhexidine rinse for 2 weeks postoperatively and to avoid trauma or pressure at the surgical site. Toothbrushing activities in the operated sites were discontinued during this time. The dressing and sutures were removed 10 days after surgery, home care instructions were given. Professional prophylaxis was done weekly for the first month and then at 3-month interval.

\section{Clinical observations}

Healing was uneventful. At 4 weeks, her plaque control was not good and the gingiva at the surgical site was edematous and reddish

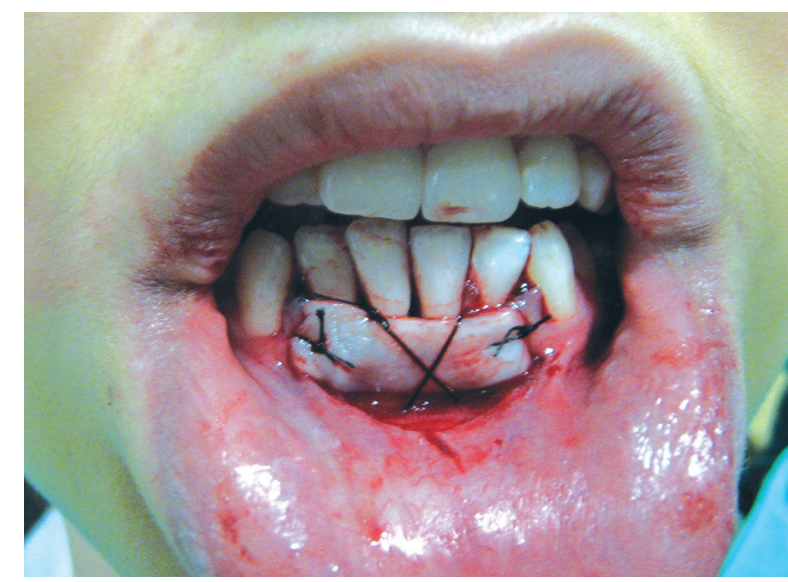

Figure 2. Free gingival graft sutured in place. The roots are covered to the level of the CEJ.

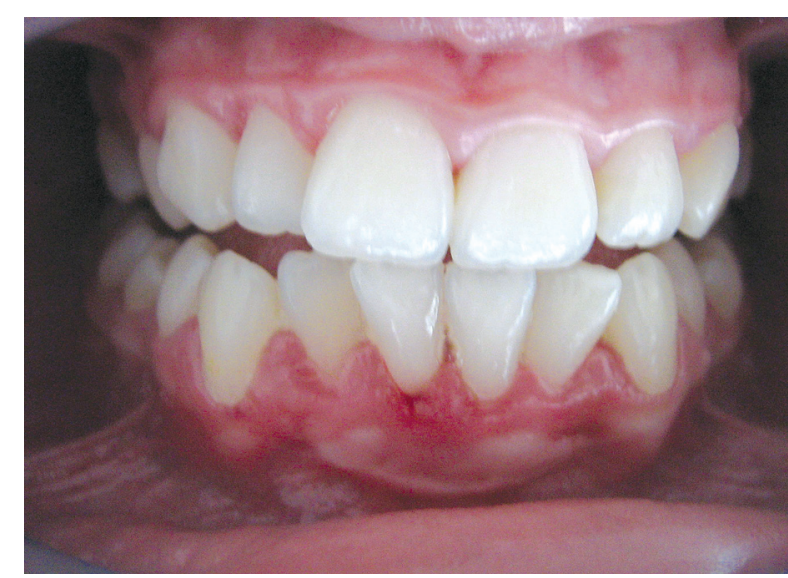

Figure 4. Clinical view at 4 months post-surgery. Normal appearance was established, with a significant increase of keratinized attached gingiva and a free gingival margin that is in harmony with the neighboring teeth. 
(Figure 3). Normal appearance was established at 4 months postoperatively and the amount of attached gingiva was approximately $3 \mathrm{~mm}$. (Figure 4). At 12 months postoperatively, probing depth at the midbuccal site was less than $1 \mathrm{~mm}$, and the free gingival margin was located less than $0.5 \mathrm{~mm}$ apically to the CEJ (Figure 5).

The patient was followed for approximately 1 year postoperatively and complete tissue healing was achieved. The patient reported at her postoperative appointment that she had stopped her fingernail scratching habit.

\section{DISCUSSION}

Self-inflicted oral injuries can be premeditated or accidental or can result from an uncommon habit. These injuries usually results from a foreign object or a patient's fingernail that habitually causes an erosion of the gingival tissue in a specific area. ${ }^{19}$ There are varying degrees of self-injurious behavior from simple fingernail biting to extremes in self-mutilation. $8,12,15,18,24$ In the present case, the mechanical trauma caused by the almost constant self-injurious behavior is considered to have been the primary etiologic factor. This case serves as another opportunity to emphasize the necessity of a comprehensive history which obtains the more subtle information relative to etiology.

Habitual fingernail scratching is a common behavior among children. ${ }^{19}$ This is probably true but such injuries are not limited to children, diagnosed adolescents and adults.4,7,26 In this case, a teenage patient has a habitual fingernail scratching. Dentists need to be cognizant of the potential ramifications of fingernail scratching

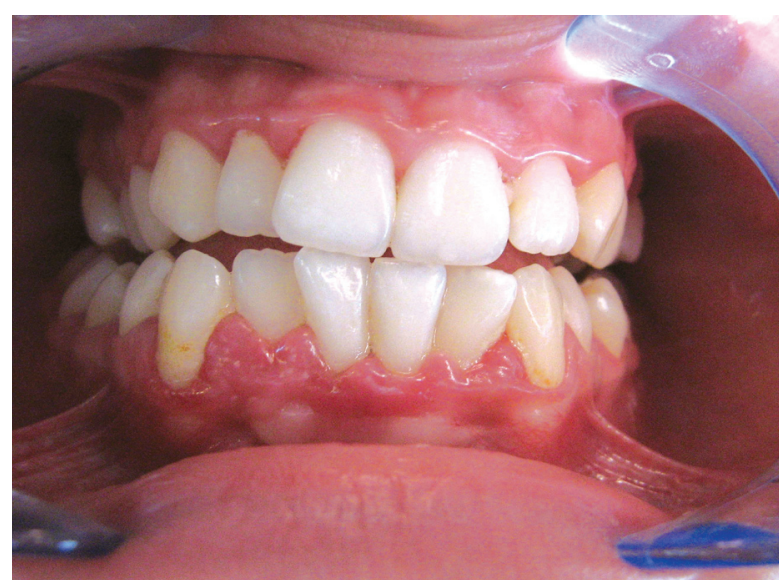

Figure 5. Clinical view at 12 months post-surgery. The gingival margin is in harmony with the neighboring teeth. including not only physical injury but also gingival recession, potential bacterial contamination (infection), inflammation, attachment loss, bone loss, and even tooth loss. The case described here demonstrates that scratching is a potential cause of localized gingival recession, attachment loss, edema and ulceration.

The etiology of self-inflicted oral injuries in adolescent and adult includes some emotional disturbance. ${ }^{20,22}$ In the case presented here, the anxiety and stress of exam are believed to have been the main reason behind the patient's behavior.

Management of patients with self-inflicted injuries is usually complicated by their lack of compliance and communication. In cases of self-inflicted injury it might be difficult the patient to stop the noxious behavior. There are no standard techniques to prevent or treat orofacial self-inflicted injuries. The treatment plan is established according to the special circumstances of the individual case. Sedation, behavior modification and restraints are usually utilized to control the destructive behavior. ${ }^{7,22-}$ ${ }^{24}$ Our patient was referred to a psychiatrist for evaluation and she was convinced that she should discontinue this habit.

In the case presented here, treatment of the gingival recession was done surgical periodontal treatment. FGGs have been utilized to increase amounts of keratinized tissue and obtain root coverage, considered necessary to improve the marginal adaptation of soft tissue to the root surfaces and to inhibit further apically-directed loss of soft tissues and bone. ${ }^{27}$ Therefore, it was decided to treat this problem with a FGG. The successful root coverage was obtained \%s ranging from 90 to $100 \%$ in class 1 and 2 gingival recession, ${ }^{26-28}$ as was demonstrated in this case.

\section{CONCLUSIONS}

This case report shows that it is possible to treat gingival injury and maintain the periodontal health of a patient with destructive habit. Patient compliance, regular dental follow-ups, and psychologic support may be useful in stabilizing the periodontal condition of these patients. Dentists must be aware that self-inflicted gingival injury, although thought to be uncommon, is quite widespread. 


\section{REFERENCES}

1. Armitage GC. Development of a classification system for periodontal diseases and conditions. Ann Periodontol 1999;4:1-6.

2. Stewart DJ. Minor self-inflicted injuries to the gingivae: gingivitis artefacta minor. J Clin Periodontol 1976;3:128132.

3. Stewart DJ. Teething, an unusual response. A case of gingivitis artefacta minor in an infant. Br Dent $J 1982 ; 152: 93-$ 94.

4. Spencer RJ, Haria S, Evans RD. Gingivitis artefacta-a case report of a patient undergoing orthodontic treatment. $\mathrm{Br} J$ Orthod 1999;26:93-96.

5. Greene PR. An unusual self-inflicted gingival injury. $\mathrm{Br}$ Dent $J 1994 ; 177: 23-24$.

6. Groves BJ. Self-inflicted periodontal injury. Br Dent $J$ $1979 ; 147: 244-246$.

7. Pattison GL. Self-inflicted gingival injuries: literature review and case report. J Periodontol 1983;54:299-304.

8. Lucavechi T, Barbería E, Maroto M, Arenas M. Self-injurious behavior in a patient with mental retardation: review of the literature and a case report. Quintessence Int 2007;38:393398.

9. Pradeep AR, Sharma DC. Gingival recession and pathologic migration due to an unusual habit. J Int Acad Periodontol 2006;8:74-77.

10. Alonso CAB, Della VD, Primo L. Self-inflicted gingival injury in a pediatric patient: a case report. $J$ Dent Child 2004;71:215-217.

11. Sepet E, Ulukapi I, Aytepe Z, Cebeci I, Aydoḡmuş Z. Factitial (self-induced) gingival disease: four case reports. Quintessence Int 2001;32:762-765.

12. Krejci CB. Self-inflicted gingival injury due to habitual fingernail biting. J Periodontol 2000;71:1029-1031.

13. Beckett H, Buxey SG, Gilmour AG. Self-inflicted gingival injury. Br Dent $J$ 1995; 178:246.

14. Rodd HD. Self-inflicted gingival injury in a young girl. $\mathrm{Br}$ Dent J 1995;178:28-30.

15. Steelman R. Self-injurious behavior: report of a case and follow-up. J Oral Med 1986;41:108-110.

16. Austin G, Mesa M, Lambert C. The Keyes technique and self-inflicted injuries. Three case reports. J Periodontol 1985;56:537-539.

17. Stewart DJ, Kernohan DC. Traumatic gingival recession in infants. The result of a dummy sucking habit. $\mathrm{Br}$ Dent $J$ 1973;135:157-158

18. Creath CJ, Steinmetz S, Roebuck R. A case report. Gingival swelling due to a fingernail-biting habit. J Am Dent Assoc 1995;126:1019-1021.
19. Blanton PL, Hurt WC, Largent MD. Oral factitious injuries. J Periodontol 1977;48:33-37.

20. Josell SD. Habits affecting dental and maxillofacial growth and development. Dent Clin North Am 1995;39:851-860.

21. Hasler JF, Schultz WF. Case report. Factitial gingival traumatism. J Periodontol 1968;39:362-363.

22. Golden S, Chosack A. Oral manifestations of a psychological problem. J Periodontol 1964;35:349.

23. Lewis TM. Gingival traumatism-A habit. $J$ Periodontol $1962 ; 33: 353$

24. Ayer WA, Levin MP. Self-mutilating behaviors involving the oral cavity. J Oral Med 1974;29:4-7.

25. Miller PD Jr. Root coverage with the free gingival graft Factors associated with incomplete coverage. J Periodontol 1987;58:674-681.

26. Rawal SY, Claman LJ, Kalmar JR, Tatakis DN. Traumatic lesions of the gingiva: a case series. $J$ Periodontol 2004;75:762-769.

27. Roccuzzo M, Bunino M, Needleman I, Sanz M. Periodontal plastic surgery for treatment of localized gingival recessions: a systematic review. J Clin Periodontol 2002;29:178-194.

28. Miller PD, Jr. Regenerative and reconstructive periodontal plastic surgery. Mucogingival surgery. Dent Clin North Am 1988;32:287-306. 